\title{
Evaluation of the rheological properties of the dough and the characteristics of the bread with the addition of purple potato
}

\author{
Sorina ROPCIUC*, Mircea OROIAN, Ana LEAHU, and Cristina DAMIAN
}

\author{
Stefan cel Mare University, Faculty of Food Engineering, 13 Universitatii Street, 720229 Suceava, Romania
}

\begin{abstract}
The aim of this study was to determine the rheological characteristics of the dough at the addition of purple potato powder in different quantities (0-100 g). The wheat flour types 480 and 1250 were used. The rheological characteristics of the dough were determined with the help of Chopin Alveograph analyzing the tensile strength. The rheological measurements were made with the HAAKE RheoWin Mars 40 rheometer and the dough's viscoelastic modulus was analyzed at the frequency of 1-20 Hz. The bread samples were analyzed in terms of volume, porosity, color and texture. The textural parameters determined with the help of the texturometer were the elasticity, adhesiveness and stickiness of the bread crumb. It has been found that the addition of purple potato dough does not adversely alter the rheological properties of the dough. The elasticity and stickiness of the bread core increases with the increase of potato addition in the case of whole-grain flour. The color of the bread intensifies as the dose of purple potato powder increases.
\end{abstract}

Keywords: anthocyanins; viscoelastic modulus; textural properties; color difference.

\section{Introduction}

Wheat bread is a widely consumed product in many countries, especially in Romania where bread consumption per capita is far above EU average. One of the main commercial products introduced into wheat flour for bread is potato flour, which is convenient for storage. Potato flour is characterized by a balanced amino acid composition, which improves the deficiency of cereal proteins and dietary fiber [1]. Although the potato is eaten mainly as a vegetable, bakers use it to change the texture and to create new assortments of bakery products. Bakers have noticed that many customers like the taste of potato in bread. There are a multitude of bakery products that are obtained by adding potato flakes or potatoes as such. Because potatoes are rich in complex carbohydrates and have a low fat content are used as ingredients in bread mixes [1]. Raw purple potato contains the following chemical constituents: crude fat (\%) - 1.29; protein (\%) 1.82; ash (\%) -3.47 ; crude fiber $(\%)$ - 2.79; iron (mg/100 g) 19.13; zinc (mg/100 g) - 0.80, carbohydrate and dietary fiber, B6 and $\mathrm{C}$ vitamins, selenium, potassium, magnesium and iron [2]. Anthocyanins are a class of flavonoid compounds responsible for the attractive blue, purple and red colors of most fruits and vegetables. In nature, hundreds of anthocyanins have been identified $[3,4]$. Anthocyanin pigments are found in plants, they are natural pigments that have shown increased interest due to the wide range of colors and beneficial effects on health. Anthocyanins can also improve the nutritional value of processed foods by preventing oxidation of lipids and proteins in the food products. Purple potato (PP) is also consumed due to its function of capturing free radicals, antimutagenic, anticancer and antihypertensive [2]. Anthocyanins are used as natural food colors, juices, bread, noodles, jams, chips and sweets [5-7].

\section{Experimental}

\subsection{Materials}

Wheat flour was bought from a local producer and was accompanied by quality documents. Two types of flour were used, white flour (type 480) and whole wheat flour (type 1250). Wheat flour used to obtain purple potato bread had the chemical characteristics presented in Table 1, as provided by the producer.

Table 1. Chemical characteristics of flour

\begin{tabular}{|c|c|c|c|c|c|c|}
\hline $\begin{array}{c}\text { Flour } \\
\text { type }\end{array}$ & $\begin{array}{c}\text { Humid- } \\
\text { ity } \\
{[\%]}\end{array}$ & $\begin{array}{c}\text { Ash } \\
{[\%]}\end{array}$ & $\begin{array}{c}\text { Moist } \\
\text { gluten } \\
{[\%]}\end{array}$ & $\begin{array}{c}\text { Gluten } \\
\text { defor- } \\
\text { mation } \\
{[\mathbf{m m}]}\end{array}$ & $\begin{array}{c}\text { Acid- } \\
\text { ity } \\
{[\%]}\end{array}$ & $\begin{array}{c}\text { FN* } \\
{[\mathbf{\%}]}\end{array}$ \\
\hline $\mathbf{4 8 0}$ & 14.3 & 0.48 & 35 & 8 & 2.4 & 292 \\
\hline $\mathbf{1 2 5 0}$ & 11.7 & 0.78 & 25.3 & 10 & 2.5 & 325 \\
\hline
\end{tabular}

$*$ FN $=$ Falling Number.

The purple potato was freshly purchased commercially. The tubers were washed, then boiled in peel for 20 minutes at $100{ }^{\circ} \mathrm{C}$, crushed and dehydrated at a temperature of $80-90{ }^{\circ} \mathrm{C}$. The dehydration was carried out using hot air convection tray drier with steel mark Hanna Instruments, dried potato pulp was finely powdered until constant weight. Fresh yeast purchased from the commercially was used.

\subsection{Dough preparation and laboratory bread making method}

The bread recipe was described as follows: $500 \mathrm{~g}$ wheat flour, $13 \mathrm{~g}$ instant flour $(60-50 \%)$. Wheat flour was replaced with $0 \%, 5 \%, 10 \%, 15 \%$ and $20 \%$ weight of purple potato powder. The dough was kneaded using the Kitchen Aid Heavy Duty mixer by mixing until full

\footnotetext{
* Corresponding author. E-mail address: sorina.ropciuc@ fia.usv.ro (Sorina Ropciuc)
} 
dough development. The flour mixture was kneaded at low rotational speed until a homogeneous dough was obtained. The dough was divided into pieces of $550 \mathrm{~g}$ and was putted in a fermenting machine for $1 \mathrm{~h}$ at $30{ }^{\circ} \mathrm{C}$ and $85 \%$ relative humidity.

Baking was conducted at $180-200{ }^{\circ} \mathrm{C}$; after baking, the bread was left to cool for 2 hours (day 0) and the textural characteristics were determined.

\subsection{Dough properties}

\subsubsection{Chopin Alveograph analyzing}

Alveographic method (SR ISO 5530-4 /2002) was used. The method is based on the tensile strength of a sheet of dough maintained to rest for a certain time and which, under the pressure of a stream of air, swells in the form of a growing bubble until it breaks [15].

\subsection{Rheological analysis}

The rheological analysis of the dough was performed on a dynamic rheometer (HAAKE RheoWin Mars 40, Germany). All measurements were performed at a temperature of $20{ }^{\circ} \mathrm{C}$, using rotor / plate geometry with a rotor diameter of $40 \mathrm{~mm}$ and a gap of $2 \mathrm{~mm}$.

The frequency range of $1-20 \mathrm{~Hz}$ and the temperature of $20{ }^{\circ} \mathrm{C}$ were used for the elastic modulus $\left(\mathrm{G}^{\prime}\right)$ and the viscous modulus $\left(\mathrm{G}^{\prime \prime}\right)$. Frequency recovery tests were performed in the linear viscoelasticity range at constant stress $50 \mathrm{~Pa}$. The whistle time was $60 \mathrm{~s}$ and the recovery stage was $180 \mathrm{~s}[16,17]$.

\subsection{Evaluation of bread quality}

2.5.1. Specific volume $(S V)$. The specific volume of bread shows the bread volume per unit weight and leavened gas retention capability within the dough mass [17-20]. Volume (mL) of bread was measured using the standard rape displacement method. The bread was weighed accurately and the volume was determined by replacing the rapeseed. The specific volume was calculated in relation to the volume and mass of the bread.

2.5.2. Determination of the porosity and elasticity of the bread. The porosity of the bread was determined by weighing a core cylinder cut from a $6 \mathrm{~cm}$ thick slice of bread, according SR 91:2007. The elasticity was determined by pressing the core of the bread and measuring its height, according SR 91:2007.
2.5.3. Texture analysis. The texture profile evaluation test aims to mimic the mastication process, which is run in the form of double compression cycles. Through this test a number of properties of the texture can be evaluated: hardness, springiness, cohesiveness, adhesiveness. The working principle consists in applying a tension on the dough samples, with the automatic recording of the resistance force that it opposes to the deformation. Through the software, the device was programmed to apply the tensile force to the double compression sample. Because it is a fermented dough, its deformation is considered at the first double, it has a tendency to return.

Compression was performed up to a displacement equal to $75 \%$ of the sample height with a pressing speed of $4 \mathrm{~mm} / \mathrm{s}$. The test parameters were as follows: 10.0 $\mathrm{mm} / \mathrm{s}$ pre-test speed, $5.0 \mathrm{~mm} / \mathrm{s}$ test speed, $5.0 \mathrm{~mm} / \mathrm{s}$ posttest speed and $40 \%$ strain. Thus, the device software was programmed to record the forces and displacements as such as well as the calculation of the texture parameters derived from the integration of the two recorded parameters. All tests were carried out after the samples were cooled down for $2 \mathrm{~h}$.

2.5.4. Determining the color of the bread. The color determination was performed with the Konica Minolta CR400 / 410 colorimeter, the values $L^{*}$ are determined. Three values are taken from the same sample, from different points, and their arithmetic mean was made.

2.5.5. Sensory evaluation. The sensory assessment of the purple potato bread was performed by a team of 10 experienced tasters using the scale method with a score between 1 and 5 points.

\subsection{Statistical analysis}

The results obtained were statistically processed using the XLSTAT program, version 2021 and statistical significance was determined at 0.05 levels $(\mathrm{p} \leq 0.05)$.

\section{Results and discussions}

\subsection{Influence of powder purple potato on alveograph dough rheological properties}

The addition of powder purple potato to wheat flour dough decreased the water absorption values (Table 2) which were $6.8 \%$ lower for the dough sample with $20 \%$ PP addition compared to the control.

Table 2. The results of the alveographic curve parameters for the doughs obtained from flour F_480 and F_1250

\begin{tabular}{|c|c|c|c|c|c|}
\hline Sample & WA (\%) & $\mathbf{P}(\mathrm{mm})$ & $\mathbf{L}(\mathbf{m m})$ & $\mathrm{W}\left(10^{-4} \mathrm{~J}\right)$ & $\mathbf{P} / \mathbf{L}$ \\
\hline S0_480 & 60 & 135 & 43 & 197 & 3.14 \\
\hline S1_480 & 58.6 & 41 & 49 & 85 & 1.21 \\
\hline S2_480 & 57.2 & 52 & 43 & 69 & 0.84 \\
\hline S3_480 & 55.3 & 32 & 53 & 51 & 0.54 \\
\hline S4_480 & 53.2 & 23 & 59 & 49 & 0.43 \\
\hline S0_1250 & 60.4 & 143 & 26 & 179 & 5.5 \\
\hline S1_1250 & 59.4 & 113 & 25 & 109 & 4.35 \\
\hline S2_1250 & 57.8 & 96 & 26 & 84 & 3.84 \\
\hline S3_1250 & 55.8 & 93 & 25 & 88 & 3.52 \\
\hline S4_1250 & 52.7 & 93 & 20 & 81 & 4.65 \\
\hline
\end{tabular}

WA = water absorption.

Alveograph parameters: $\mathrm{P}=$ tensile strength of the dough; $\mathrm{L}=$ extensibility; $\mathrm{W}=$ deformation energy of the dough. Sample: S0 (0\% PP); S1 (5\% PP); S2 (10\% PP); S3 (15\% PP); S4 (20\%PP).

The alveographic results obtained for the doughs obtained from F480 and F1250 flour supplemented with different percentages of purple potato powder, are presented in Table 1. The tensile strength of the dough 
increases with increasing potato dose. This is explained by the fact that the added potatoes replace the flour and the gluten content is reduced. The pasting properties of dough are related to the content of starch in amylose and the swelling power of starch. The content of starch increased and the content of gluten protein decreased with the addition of potato starch. The highest value is recorded in the control sample (S0_480) being 135 compared to the value determined in sample 4 (S4_480), which is 23. The same decreasing trend of tensile strength is noticed in type 1250 flour, but with a smaller difference between control sample and sample 4, with the addition of $20 \%$ purple potato. The increase in extensibility in the analyzed samples is explained by the fact that the dough contains more starch due to the addition of potatoes which increases its extensibility. The highest value is recorded in sample 4, being 59 compared to 43. The dough samples from flour 1250 show values of dough toughness between values 26 and 20 . The value of extensibility increases when adding the dose of potato.

The deformation energy of the dough is influenced by the change in gluten in the dough. The energy value decreases as the dose of potatoes added increases. The data obtained show that the addition of starch to the dough reduces the elasticity of the dough, which means that the resistance of the dough to stretching decreases. The tensile strength / extensibility of the analyzed samples expresses the ratio between the elastic and viscous properties of the dough. The highest value is recorded in the control sample, of 3.14 compared to 0.43 in sample 4, being the highest dose of potato.

The hydrating capacity of the flour decreased as the dose of potato powder increased. The absorption of water in the flour mix decreases with the decrease of the amount of gluten by substituting wheat flour with potato flour.

Some researchers replaced wheat flour with potato flour in a proportion of $0-35 \%$ and found the same properties of the dough in terms of extensibility, viscosity and stickiness [21, 23, 24].

\subsection{Rheological properties of dough}

Figures 1-2 shows that the elastic modulus, $G^{\prime}$ and viscous the modulus, $G^{\prime \prime}$ of the dough decreased as the amount of starch increased. Test results showed that the addition of potatoes affected the viscoelasticity of the dough, which has predominantly viscous rheological characteristics. The rheological properties of the dough depends on the gluten and starch content and the granular structure of the starch [25]. The addition of potato starch decreased the overall gluten content. This weakened the structure of the dough and affected elasticity and fluidity, leading to an increase in viscous modulus and elastic modulus [26]. The decreasing trend of $G^{\prime}$ and $G^{\prime \prime}$ for potato dough is in line with previous research $[27,28]$.

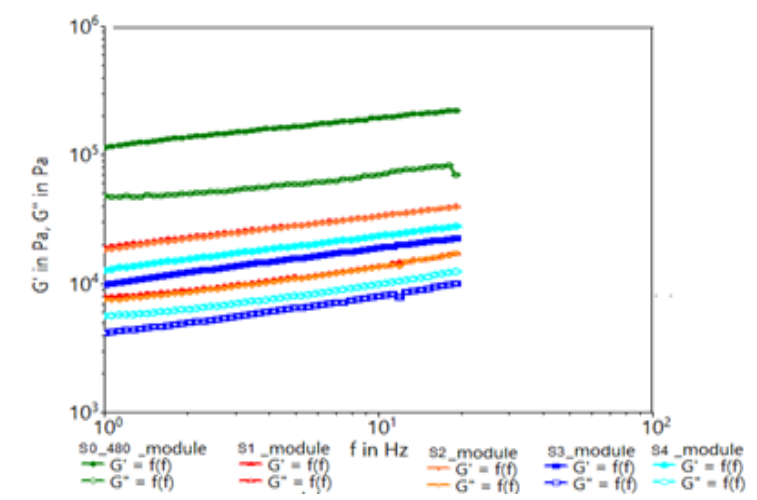

Figure 1. Viscoelastic module for flour dough type 480

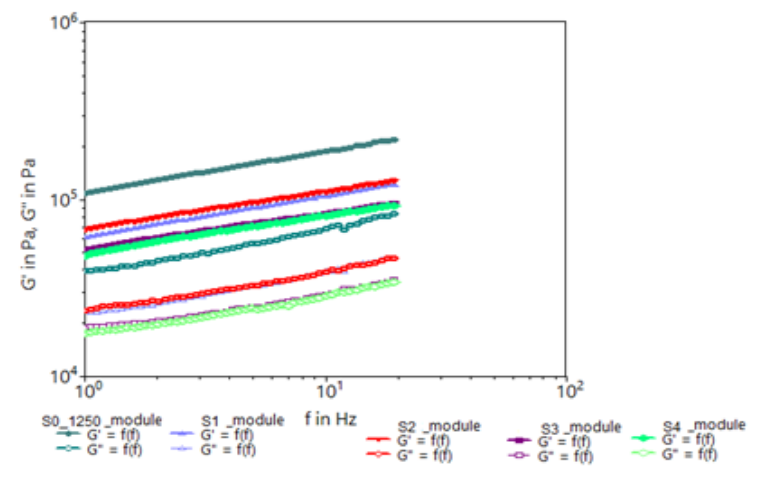

Figure 2. Viscoelastic module for flour dough type 1250

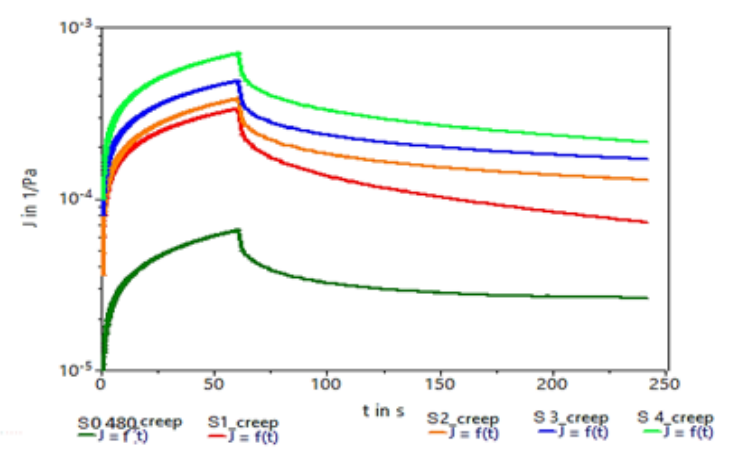

Figure 3. The creep recovery curve for flour dough type 480

Figure 3 describes the behavior of the viscoelastic characteristics of the dough with the ability to return to its initial structure after removing the applied stress. It can be seen that as the purple potato is added, the behavior of the dough increases. As the concentration of purple potato decreases, we implicitly observe a decrease in the maximum deformation and a deficiency in the elastic recovery [28]. Purple potato powder improves the extensibility and resilience of the 1250 flour dough for the addition of $5-15 \%$ potato powder (Figure 4). The lowest return capacity is noted in sample 4 (20\% PP) which has the lowest return capacity. 


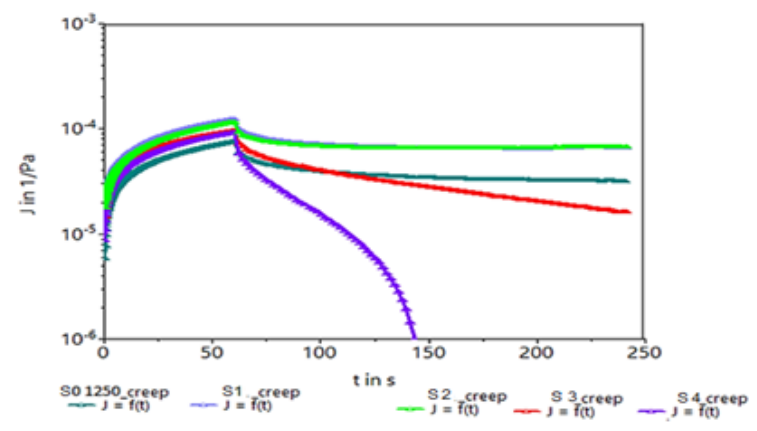

Figure 4. The creep recovery curve for flour dough type 1250

\subsection{Evaluation of bread quality}

The addition of potato powder significantly improves the volume of the bread (Table 3 ). The specific volume increases for high proportions of purple potato in flour 1250 and decreases with increasing percentage of potato powder in flour from type 480 flour. The bread obtained from 1250 flour is notable for a significant increase in volume compared to the control sample. The quality of the core is also greatly improved with the increase of the addition of potato powder [29].

Table 3. Bread quality evaluation results

\begin{tabular}{cccc}
\hline Sample & Specific volume $\left(\mathbf{c m}^{\mathbf{3} / 100} \mathbf{g}\right)$ & Porosity $(\boldsymbol{\%})$ & Elasticity $(\boldsymbol{\%})$ \\
\hline S0_480 & 257.64 & 65.17 & 87.5 \\
S1_480 & 264.82 & 73.86 & 75 \\
S2_480 & 266.26 & 73.86 & 75 \\
S3_480 & 286.15 & 83.10 & 70 \\
S4_480 & 273.84 & 98.05 & 50 \\
S0_1250 & 219.78 & 92.29 & 58.82 \\
S1_1250 & 270.68 & 84.40 & 66.67 \\
S2_1250 & 283.06 & 83.10 & 66.67 \\
S3_1250 & 283.48 & 76.18 & 83.88 \\
S4_1250 & 294.8 & 72.71 & 93.33 \\
\hline
\end{tabular}

The increase in core elasticity is due to changes in pore structure that become larger and less compact compared to control samples. For both types of flour there is the same tendency to increase the porosity of the bread. Similar results were observed in other research on the microstructure and characteristics of bread with the addition of potato powder $[27,28]$.

\subsection{The results of parameters of Texture Profile} Analysis (TPA)

The hardness of the bread core increases significantly as the proportion of purple potato added to all samples obtained from white flour increases (Table 4). The hardness of the core is low bread whole meal bread obtained. Springiness in all bread samples shows constant value. The cohesiveness shows high but insignificant values as the percentage of potato powder increases. Previous research has shown that the textural properties of bread and dough have a positive relationship with protein content and quality of flour proteins. In this research the results obtained from the TPA parameters showed that the addition of potato powder showed a negative effect on the textural properties of white bread. This may be due to a lack of gluten in the potato powder. Gluten proteins are the main proteins in flour, which can form a network and give to dough unique viscoelastic properties.

Table 4. Bread texture analysis results

\begin{tabular}{|c|c|c|c|c|c|c|}
\hline Sample & $\begin{array}{c}\text { Hardness } \\
\text { [g] }\end{array}$ & Springiness & Cohesiveness & $\begin{array}{c}\text { Chewiness } \\
\text { [g] }\end{array}$ & $\begin{array}{c}\text { Adhesiveness } \\
{[\mathbf{J}]}\end{array}$ & Resilience \\
\hline S0_480 & 391.5 & 1 & 0.79 & 328.1 & -0.9 & 2 \\
S1_480 & 600.4 & 1 & 0.81 & 571.5 & -1.2 & 2.3 \\
S2_480 & 609.4 & 1 & 0.83 & 554.7 & -1.6 & 2.1 \\
S3_480 & 655.7 & 1 & 0.89 & 534.5 & -1.8 & 1.8 \\
S4_480 & 614.5 & 1 & 0.89 & 516.6 & -3.0 & 2.2 \\
\hline S0_1250 & 414.1 & 1 & 0.89 & 383.6 & -0.01 & 2.3 \\
S1_1250 & 294.6 & 1 & 0.88 & 373.3 & -0.05 & 2.2 \\
S2_1250 & 361.3 & 1 & 0.88 & 314.6 & -1.33 & 1.9 \\
S3_1250 & 254.3 & 1 & 0.85 & 226.7 & -1.61 & 1.2 \\
S_1250 & 146.3 & 1 & 0.85 & 133.2 & -1.88 & 1.2 \\
\hline
\end{tabular}

\subsection{Bread color results}

The bread samples were analyzed from the point of view of the color spectrum and the color intensity of the bread core when increasing the percentage of purple potato powder. There is an increase in the difference in brightness $(\Delta \mathrm{L})$ when increasing the dose of powder added both for the samples of white flour bread and for bread with type 1250 flour. The white bread samples did not show an intense purple color trend but were in the same bread color scale for which 1250 flour was used. The color trend was similar for both types of flour. Figure 5 shows the results obtained in determining the brightness variation in the bread samples with white flour and whole wheat flour. The addition of potato 
powder changes the color of white bread but also significantly influences the whole wheat bread. It is observed that the addition of purple potato powder influences the brightness to a value comparable to that of whole wheat bread.

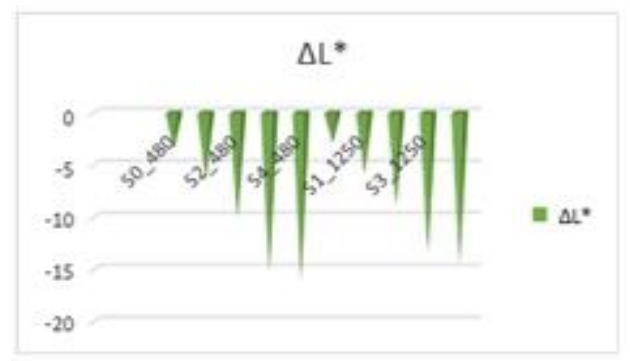

Figure 5. Graphical representation of the brightness of the bread samples

3.6. Sensory evaluation of control bread and breads with powder potato purple added

Findings of the sensory evaluation proposed that samples of bread that were obtained with the addition of $10-20 \%$ purple potato powder were assessed with a maximum of 5 points for color, core porosity and shell appearance. The taste of the bread with the addition of $5-10 \%$ purple potato powder was assessed with a maximum score, respectively 5 points compared to the control samples. The addition of purple potato powder decreases the brightness value compared to the control samples [33, 34]. According to Gómez et al. [31], increasing the amount of potato powder can enhance the Maillard reaction which could make the crust browner.

\subsection{Statistical interpretation on results and statistical correlations}

The graph describing the grouping of textural characteristics using the PCA mix represents the distances between the variable categories in the factor space. The smaller the distance between the variables, the more significant the strength of the connections. On the F2 axis, cohesiveness and adhesiveness are distributed in a strong correlation (0.5), this association describes the texture of the bread with the addition of potatoes. The adhesiveness is noticeable in this bread assortment due to the addition of potatoes and the cohesiveness describes the structure of the bread in section, elastic, without changing its structure at compression.

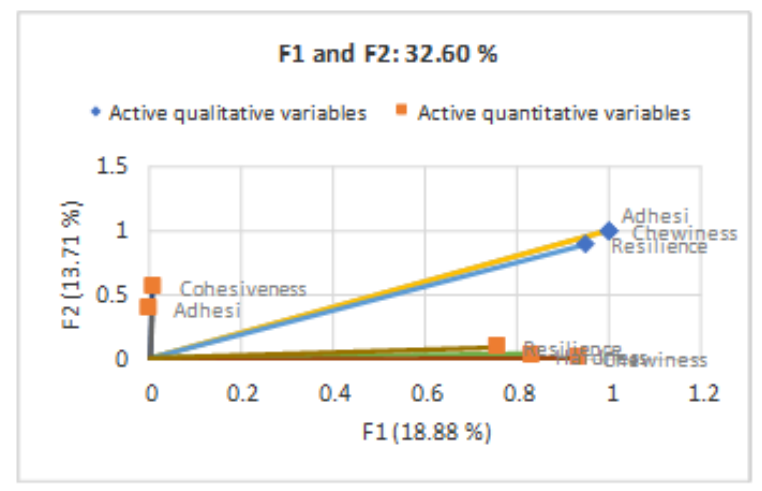

Figure 6. The PCA-mix plot for textural characteristics and dough characteristics
In Figure 7 are represented by a PCA graph the distribution of the bread assortments without the addition of potatoes and with the addition of potatoes in different proportions and the connections between them. The distribution and strength of the connections between the samples is noticeable by the fact that the control sample with 480 flour is distributed differently, the samples with low content of potato powder are associated in separate quadrants and those with powder addition in percentage of $15-20 \%$ are distributed in quadrants different. The distance between the bread samples and the distribution in different quadrants indicate significant differences between the sensory and physico-chemical characteristics.

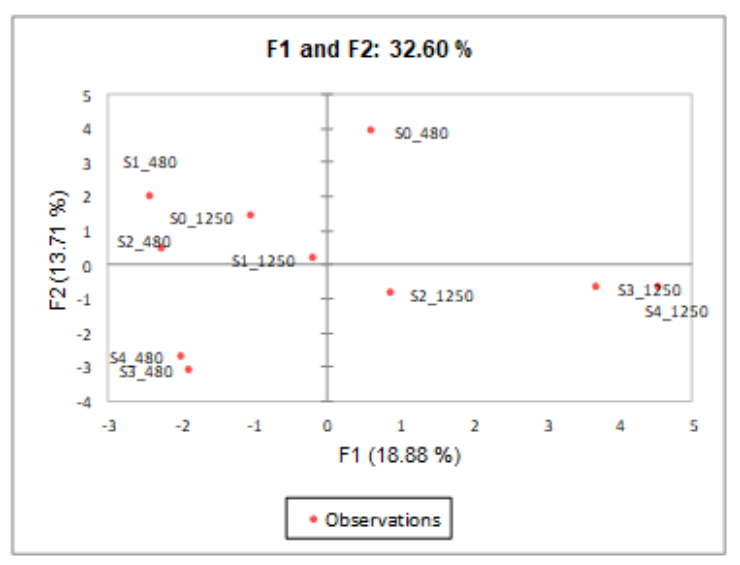

Figure 7. Graphic representation of the main components of the bread assortments

\section{Conclusions}

Addition of purple potato powder to the wheat flour influenced the dough rheological properties and bread quality such as increased the specific volume and porosity. The Alveograph characteristics of the dough showed a decrease in tenacity, extensibility and deformation energy as the percentage of purple potato powder increased and compared to the control sample. Purple potato powder had a pronounced effect on properties of the dough, leads to decreased water absorption and lower extensibility of the dough in comparison with control bread.

The evaluators favorably appreciated the sensory characteristics of the bread with the addition of purple potato powder. The scores obtained for the sensory analysis led to the acceptability of the product by consumers. The color of the bread was of interest to the evaluators and was marked with a maximum score.

In addition, potato purple flour addition improved bread texture analysis, decreases the hardness of the bread as the percentage of purple potato flour increases. Additions of purple potato powder to wheat flour type 480 (at $5-15 \%$ level) generally produced bread similar to that obtained from flour type 1250 without any visible deterioration of acceptability.

Therefore, purple potato bread is recommended for its textural and sensory characteristics.

\section{Conflict of interest}

Authors declare no conflict of interest. 


\section{References}

[1]. V. Bártová, J. Bárta, A. Brabcová, K. Zdráhal, V. Horáčková, Amino acid composition and nutritional value of four cultivated South American potato species, Journal of Food Composition and Analysis 40 (2015) 78-85.

[2]. Q.A. Curayag, E.I. Dizon, W.A Hurtada, F. Yildiz, Antioxidant activity, chemical and nutritional properties of raw and processed purple-fleshed sweet potato (Ipomoea batatas Lam.), Cogent Food \& Agriculture 5 (2019) 1-13.

[3]. H.W. Kim, J.B. Kim, S.M. Mi, N.C. Lee, Y.M. Chu, S.M. Che, J.H. Kim, S.N. Kim, S.Y. Cho, Y.S. Anthocyanin changes in the Korean purplefleshed sweet potato, Food Chemistry 130 (2012) 966-972

[4]. I. Aoran, X. Ruoshi, H. Sijia, A. Xiaoyu, H. Yi, W. Chengtao, Y. Sheng, B. Wang, S. Xuewei, H. Jingren, Research advances of purple sweet potato anthocyanins: extraction, identification, stability, bioactivity, application, and biotransformation, Molecules 24 (2019) 24-29.

[5]. X.L. Liu, T.H Mu, H.N. Sun, M. Zhang, J.W. Chen, Influence of potato flour on dough rheological properties and quality of steamed bread, Journal of Integrative Agriculture 15 (2016) 2666-2676.

[6]. A. Castañeda-Ovando, M.L. de PachecoHernández, M.E Páez-Hernández, J.A. Rodríguez, C. Galán-Vidal, Chemical studies of anthocyanins: A review, Food Chemistry 113 (2009) 859-871.

[7]. Z. Long, Z. Linglong, B. K. Xiaofeng, G. Lu, Z. Cunxu, Characterization and comparative study of starches from seven purple sweet potatoes, Food Hydrocolloids 80 (2018) 168-176.

[8]. I. Suda, F. Ishikawa, M. Hatakeyama, M. Miyawaki, T. Kudo, K. Hirano, A. Ito, O. Yamakawa, S. Horiuchi, Intake of purple sweet potato beverage effects on serum hepatic biomarker levels of healthy adult men with borderline hepatitis, European Journal of Clinical Nutrition 62 (2008) 60-67.

[9]. Z.F. Zhang, S.H. Fan, Y.L. Zheng, J. Lu, D.M. Wu, Q. Shan, B. Hu, Purple sweet potato color attenuates oxidative stress and inflammatory response induced by D-galactose in mouse liver, Food and Chemical Toxicology 47 (2009) 496501.

[10]. S. Lim, J. Xu, J. Kim, T.Y. Chen, X. Su, J. Standard, E. Carey, J. Griffin, B. Herndon, B. Katz, Role of anthocyanin-enriched purple-fleshed sweet potato P40 in colorectal cancer prevention, Molecular Nutrition \& Food Research 57 (2013) 1908-1917.

[11]. D. M. Santiago, K. Matsushita, T. Noda, K. Tsuboi, D. Yamada, D. Murayama, H. Koaze, H. Yamauchi, Effect of purple sweet potato powder substitution and enzymatic treatments on bread making, Journal of Food Science and Technology 3 (2015)159-65.

[12]. E. Rodriguez-Sandoval, G. Sandoval, M. CortesRodríguez, Effect of quinoa and potato flours on the thermomechanical and bread making properties of wheat flour, Brazilian Journal of Chemical Engineering 29 (2012) 503 - 510.

[13]. A.R. Yadav, M. Guha, R.N. Tharanathan, R.S. Ramteke, Influence of drying conditions on functional properties of potato flour, European Food Research and Technology 22 (2006) 553560.

[14]. G.G. Codina, Influence of flour quality with different extraction ratio on the rheological properties of uniaxial extension induced by the mixolab, Journal of Agroalimentary Processes and Technologie 14 (2008) 119-122.

[15]. SR ISO 5530-4- Wheat flour (Triticum aestivum L.) - Physical characteristics of doughs - Part 4: Determination of rheological properties using an Alveograph, (2002).

[16]. A. Misra, K. Kulshrestha, Potato flour incorporation in biscuit manufacture, Plant Foods for Human Nutrition 58 (2003) 1-9.

[17]. P.Ł. Kowalczewski, K. Walkowiak, Ł. Masewicz, O. Bartczak, J. Lewandowicz, P. Kubiak, H.M. Baranowska, Gluten-Free Bread with Cricket Powder-Mechanical Properties and Molecular Water Dynamics in Dough and Ready Product, Foods 8 (2019) 240-252.

[18]. SR:91- Paine si Produse de Patiserie, Metode de Analiza; ASRO Publisher House: Bucharest, (2007).

[19]. J. Korus, L. Juszczak, R. Ziobro, M. Witczak, K. Grzelak, M. Sójka, Defatted strawberry and blackcurrant seeds as functional ingredients of gluten-free bread, Journal Texture Studies 43 (2012) 29-39.

[20]. A. Mondal, A.K. Datta, Bread baking - A review, Journal of Food Engineering, 86 (2008) 465-474.

[21]. S.K. Maktouf, B. Jeddou, C. Moulis, H. Hajji, M. Remaud-Simeon, R. Ellouz-Ghorbel, Evaluation of dough rheological properties and bread texture of pearl millet-wheat flour mix, Journal of Food Science and Technology 53 (2016) 2061-2066.

[22]. A. Romano, G. Toraldo, S. Cavella, P. Masi, Description of leavening of bread dough with mathematical modelling, Journal of Food Engineering 83 (2007) 142-148.

[23]. D. Kumar, M. Taihua, M. Mengmei, Effects of potato flour on dough properties and quality of potato-wheat-yogurt pie bread, Nutrition \& Food Science 50 (2019) 885-901.

[24]. S. Hongrui, L. Xiangying, T. Zhigang, F. Jieying, M. Yue, N. Xiping, Y. Zhiqiang, Z. Xianpeng, K. Lining, Influence of Potato Flour on Dough and Steamed Bread Quality and Correlation Analysis, International Journal of Food Engineering 16 (2020) 464-470.

[25]. N. Asad, X. Zhouyi, L. Qing, X. Hanguo, L. Jing, C. Lei, W. Pengkai, W. Noman, I. Sana, J.M. Regenstein, Effect of wheat flour replacement with potato powder on dough rheology. physiochemical and microstructural properties of instant noodles, Journal of Food Processing and Preservation 43 (2019) 127-138. 
[26]. T. Chunsheng, W. Kejian, L. Xuejun, G. Ertong, Effects of potato starch on the properties of wheat dough and the quality of fresh noodles, CyTA Journal of Food 18 (2020) 427-434.

[27]. J. Li, G. G. Hou, Z. X. Chen, A. L. Chung, K. Gehring, Studying the effects of whole-wheat flour on the rheological properties and the quality attributes of whole-wheat saltine cracker using SRC, alveograph, rheometer, and NMR technique, Food Science and Technology LWT 55 (2014) 4350.

[28]. X. L. Cao, S. M. Zhou, C. P. Yi, W. Li, H. F. Qian, H Zhang, X.G. Qi, Effect of whole flour on the quality, texture profile and oxidation stability of instant fried noodles, Journal of Texture Studies 48 (2017) 607-615.

[29]. X. Fen, H. Honghai, L. Qiannan, D. Xiaofeng, Z. Hong, Rheological and microstructural properties of wheat flour dough systems added with potato granules, International Journal of Food Properties 20 (2017) S1145-S1157.

[30]. W. Kun-Lun, S. Wen-Chieh, Y. Chuan-Hua, Characteristics of dough and bread as affected by the incorporation of sweet potato paste in the formulation, Journal of Marine Science and Technology 17 (2009) 13-22.

[31]. CIE. Colorimetry, 2nd Edition ed; Publication CIE No 15.2; Central Bureau of the Commission
Internationale de L'Eclairage: Vienna, Austria, 1986.

[32]. V. Jovanka, J. Popov-Raljić, S. Mastilović, G. Jovanka, P. Laličić, S. P. Vladimir, Investigations of bread production with postponed staling applying instrumental measurements of bread crumb color, Sensors 9 (2009) 8613-8623.

[33]. M. Gómez, F. Ronda, C. A. Blanco, P. A. Caballero, A. Apesteguía, Effect of dietary fiber on dough rheology and bread quality, European Food Research Technology 216 (2003) 51-56.

[34]. W. Kun-Lun, S. Wen-Chieh, Y. Chuan-Hua, Characteristics of dough and bread as affected by the incorporation of sweet potato paste in the formulation, Journal of Marine Science and Technology 17 (2009) 13-22.

[35]. K. Matsushita, J. Iwata, D. Goshima, D. M. Santiago, T. Nakamura, H. Yamauchi, Bread making improvement of mashed potatosupplemented dough by treating with optimal bakery enzymes, Food Science and Technology Research 25 (2019) 245-255.

Received: 28.09.2021

Received in revised form: 09.11.2021

Accepted: 10.11.2021 